\title{
La odontología en nuestros días
}

\author{
Dentistry in our country
}

\author{
Yolanda Valero Princet*
}

En los últimos tiempos, la población de nuestro país ha alcanzado un promedio de edad más alto que el de otras épocas, lo cual ha provocado que el número de las personas de 65 años de edad o más también haya crecido. Esta nueva longevidad ha traído a su vez un incremento en la cantidad de pacientes enfermos o con ciertas discapacidades, como consecuencia del deterioro natural que la edad acarrea consigo. Los problemas dentales que conlleva una edad avanzada, así como la obesidad, el VIH sida, la resistencia a antibióticos, el tabaquismo y el alcoholismo, entre otros más, son más frecuentes que antaño.

En el caso específico de los dientes, resulta curioso que la mayoría de la gente no piense en la boca como una parte importante del cuerpo, pues en la realidad existe una gran cantidad de enfermedades relacionadas con ellos. Numerosas investigaciones destacan hoy la estrecha relación entre la salud bucal y la general. Algunos ejemplos de ello son las infecciones neumónicas y las enfermedades periodontal y ateroesclerótica, así como sus consecuencias como los partos prematuros, entre otras.

Por otro lado, los tratamientos dentales -cosméticos o no- cada vez son más solicitados no sólo por pacientes con compromiso médico, sino incluso por personas sanas. Esta novedad coloca al profesionista de la salud bucal en la necesidad de conocer una multitud de condiciones médicas como parte crítica de su formación. Sólo con una profunda capacitación en el área médica estaremos en posibilidad de ofrecer altos estándares de servicios de salud bucal.

La formación continua del odontólogo es fundamental, pues él deberá contar con la preparación necesaria para reconocer y prevenir problemas médicos asociados al tratamiento dental y referir correctamente a los pacientes con el especialista adecuado, sobre todo porque algunos —casi todos- llegan sin diagnóstico, otros conocen su enfermedad, pero no siguen tratamientos, mientras que otros siguen estrictos regímenes farmacológicos. La capacidad del cirujano dentista debe permitirle identificar la sintomatología de su paciente, entender el diagnóstico y conocer las interacciones far- macológicas entre el tratamiento médico y los medicamentos que se usarán durante el tratamiento dental.

De manera análoga, el odontólogo del futuro debe estar suficientemente preparado para prestar atención a las urgencias médicas que se presenten durante las consultas dentales y para atender los casos que ocurran en su ambiente de trabajo, estabilizándolos, en primer lugar, y luego entregándolos al servicio médico con el fin de que reciban el tratamiento definitivo.

Todo lo anterior revela que la formación de los nuevos profesionistas del área de la salud bucal se torna compleja, pues se trata de una disciplina que requiere amplios conocimientos científicos, tecnológicos y, además, el odontólogo debe contar con una amplia capacitación en las ciencias básicas y biomédicas. No obstante, cumplir este perfil lo colocará en un lugar privilegiado en el ejercicio de su profesión, lo que le retribuirá grandes satisfacciones.

Hay que añadir que esto no es privativo de los odontólogos de práctica general; también los especialistas que se han desempeñado durante años deben mantenerse en constante capacitación.

Finalmente, es esencial subrayar que todo odontólogo, joven o con años de desempeño, debe basar su práctica en un profundo cuidado de los tejidos vivos, en un gran respeto por la vida y, sobre todo, en una ética inquebrantable.

Dirección para correspondencia:
Yolanda Valero Princet
E-mail: mvalero@uic.edu.mx

* Directora de la Facultad de Odontología. Universidad Intercontinental.

C 2017 Universidad Nacional Autónoma de México, [Facultad de Odontología]. Este es un artículo Open Access bajo la licencia CC BY-NC-ND (http://creativecommons.org/licenses/by-nc-nd/4.0/).

Este artículo puede ser consultado en versión completa en http://www.medigraphic.com/facultadodontologiaunam 